\title{
DÍAZ REVORIO, Francisco Javier (2009). Los Derechos Humanos ante los nuevos avances cientificos y tecnológicos. Genética e Internet ante la Constitución. Valencia - Ciudad de México: Tirant lo Blanch - Centro Nacional de los Derechos Humanos, 426 pp.
}

Durante la segunda mitad del siglo XX la humanidad fue testigo de un inusitado desarrollo del conocimiento humano, el que originó básicamente tres "revoluciones" que impactaron de lleno en la configuración y estructura de nuestras sociedades actuales: la revolución de la física, específicamente de la energía nuclear; la revolución de la informática, asociada directamente a la masificación de las tecnologías de información y comunicación; y la revolución biotecnológica o "revolución del ADN"1. De ellas derivó una rápida ampliación de la investigación científica a una serie de aplicaciones hasta ayer imaginadas, pero hoy posibles, provocando un cambio notable y decisivo en la sociedad contemporánea y en la cultura occidental actual, lo que ha generado grandes expectativas en torno a lo técnico y lo científico; sus efectos nos preocupan a todos y somos testigos de un progreso científico que es idea remota, pero actuante; algo promisorio, pero también peligroso, aquello que puede transformar la vida para bien o para $\mathrm{mal}^{2}$.

El libro que presentamos se centra en el análisis de este fenómeno provocado por el avance científico y tecnológico principalmente en dos áreas: la medicina genética y las tecnologías de la información (TIC), pero sin perder de vista que es un estudio estrictamente jurídico-constitucional, pues de hecho a la primera cuestión crítica que se enfrenta el autor es que precisamente su objeto de estudio trasciende a la Ciencia Jurídica. No obstante, se hace cargo de ello entendiendo que el Derecho, como instrumento de regulación de la vida social, es un instrumento que sirve para dar respuesta a los nuevos hechos que demanda el tratamiento de las nuevas temáticas propuestas en este estudio.

En el caso concreto de este trabajo, el autor ya había tenido la intuición de que el tema a tratar planteaba una rica problemática desde la perspectiva constitucional, y en esa línea apuntaron acercamientos previos ${ }^{3}$ en donde se explaya en torno a la adaptación de las normas constitucionales

1 Lacadena Calero, Juan Ramón (2000). "Seréis como Dioses". Revista Crítica, No 874, pp. $12-16$

Lolas STEPKe, Fernando (2003). "Genómica, Sociedad y Bioética". Colección Ideas, año 4, No 31, mayo, pp. 5-12.

Díaz ReVorio, Francisco Javier (1997). Valores superiores e interpretación constitucional, Madrid: Centro de Estudios Constitucionales; y Díaz Revorio, Francisco Javier (2000). "Tribunal Constitucional y Derechos no Escritos". En Estín Templado, E. y Díaz Revorio, F.: La Justicia Constitucional en el Estado Democrático, Valencia: Tirant lo Blanch, pp. 231-259. 
al cambio social; al rol de la interpretación constitucional de derechos fundamentales, y más específicamente a la posibilidad de que por vía jurisprudencial sea posible justificar y reconocer derechos no escritos en los textos constitucionales, evidenciando la necesidad de contar con nuevos parámetros interpretativos.

Desde esa base teórica, Díaz Revorio se dedica esta vez a resolver la cuestión de cuál es la respuesta jurídica que el constitucionalismo en general, y en particular el Derecho Constitucional espańol, puede ofrecer a las numerosas situaciones problemáticas que se plantean en los temas a analizar y, en su caso, si en el futuro es necesario modificar, completar o adaptar esa respuesta.

Además, este trabajo aporta datos relevantes sobre el propio perfil de nuestra disciplina y sobre su sentido en el mundo globalizado del siglo XXI, colaborando en definitiva, a delimitar el contenido y sentido propio del Derecho Constitucional actual, especialmente en el ámbito de los derechos fundamentales, objetivo que desarrolla desde una perspectiva dinámica y evolutiva, asumiendo que su estudio conlleva el planteamiento de dos consecuencias: por una parte, implica la posibilidad de plantear el reconocimiento de "nuevos derechos constitucionales" o la ampliación del catálogo de derechos con nuevas manifestaciones hasta ahora desconocidas o imprevistas; y por otra, conlleva además a la constatación de nuevas amenazas o peligros para otros derechos o valores constitucionales.

En este sentido, el gran reto que nos impone el desarrollo científico y tecnológico en genética y TIC, es el de afianzar los valores del constitucionalismo, principalmente a través de la respuesta a nuevas necesidades éticas de individuos que viven $-\mathrm{y}$ conviven- en un contexto globalizado. Esta cuestión no es menor en el análisis de Díaz Revorio, puesto que con ello evidencia que es la institucionalidad del Estado constitucional de Derecho la que no resulta suficiente para dar respuesta a estos desafíos, ya que estos sí pueden ser asumidos desde la base axiológica que contemplan las Cartas fundamentales, siempre y cuando seamos capaces de estructurar nuevos principios o derechos más concretos, lo que impone a su vez la necesidad de desarrollar a través de la interpretación los valores constitucionales, a través de la incorporación de criterios de determinación claros para estos nuevos derechos; de la precisión de sus elementos esenciales; y de la configuración de vías para su reconocimiento, fundamentación y protección.

Este es el contexto general que posibilita plantear importantes desafíos al Derecho constitucional, ya que el reciente desarrollo científico en biotecnología e informática y comunicación está pidiendo una postura clara en torno al rol que efectivamente este cumple en la sociedad actual, lo que necesita de nuevas consideraciones y puntos de vista para su análisis, ya que la situación presente y futura de la relación cada vez más estrecha entre ciencia, naturaleza y sociedad nos demanda la articulación 
de un nuevo sentido para la vigencia normativa de las normas constitucionales.

\section{1) CONSTITUCIÓN Y GENÉTICA}

El progreso de la medicina en los últimos ańos ha estado marcado por el desarrollo de los procedimientos que permiten la manipulación de la composición genética de seres humanos mediante la introducción o eliminación de genes específicos. Esta posibilidad científica lleva al autor a aclarar cuáles son las relaciones entre el Derecho constitucional y la Bioética; a determinar la posición jurídico-constitucional del preembrión ${ }^{4}$ y de las células de ellos extraídas o derivadas; $y$, a analizar las implicaciones constitucionales del desarrollo genético; así como del derecho a la reproducción.

Sin desconocer el interesante aporte que la Bioética hace al Derecho en la actualidad, me parece que es necesario detenerse un poco más en los tres problemas constitucionales propiamente tales que plantea este capítulo.

En primer lugar, la determinación de la posición del preembrión ante la Norma fundamental, de acuerdo con el autor, es posible y necesaria. Por tanto, la diversidad de posturas y la incapacidad de la doctrina y de la jurisprudencia de lograr un consenso en el tema -lo que ha originado un profuso debate constitucional del que actualmente somos testigos en nuestro país- no es óbice para afirmar que la respuesta jurídica no se encuentra en la Constitución.

En el caso de Espańa, el tratamiento jurídico-constitucional del preembrión ha sido abordado por la jurisprudencia del Tribunal Constitucional ${ }^{5}$, la que ha servido -dice el autor- para afianzar una interpretación coherente con el sistema constitucional de valores hispano. En consecuencia, Díaz Revorio afirma que "El preembrión no es titular de derechos, pero le alcanza la protección constitucional de la vida y de la dignidad, dado que es un ente dotado de vida, y de carácter humano". Con ello, afirma también que "...la vida humana es objeto de una protección gradualmente creciente", tesis que por lo demás es recogida por el legislador espańol en las leyes 14/2006 de 26 de mayo, sobre técnicas de reproducción humana asistida y 14/2007 de 3 de julio, de investigación biomédica.

Blastómero o embrión preimplantatorio. "Embrión in vitro constituido por el grupo de células resultantes de la división progresiva del ovocito desde que es fecundado hasta catorce dias más tarde". Artículo 1.2 de la Ley 14/2006, de 26 de mayo, sobre técnicas de reproducción humana asistida.

5 STC 212/1996 que fallo el recurso de inconstitucionalidad interpuesto en contra de la Ley 42/1988 sobre donación y utilización de embriones y fetos humanos o sus células, tejidos u órganos y la STC 116/1999, de 17 de junio, que dirimió el recurso de inconstitucionalidad presentado en contra de la Ley $35 / 1988$, sobre técnicas de reproducción humana asistida. 
En segundo lugar, el vertiginoso desarrollo que implicó el Proyecto Genoma Humano en el ámbito de la medicina e ingeniería genética, si bien es cierto supone un gran avance en el conocimiento y tratamiento de muchas enfermedades, también sugiere que su uso inadecuado puede convertirse en una grave amenaza para la especie humana, lo que resulta contradictorio con la dignidad de las personas, "...como valor propio, común y exclusivo de nuestra especie, que se predica por igual a todos los miembros pertenecientes a la misma", razón que justifica en primer término la necesidad de contar con una protección supraestatal en esta materia.

La problemática antes expuesta implica un doble análisis para el autor: desde una perspectiva colectiva, el genoma puede considerarse como patrimonio de la humanidad, puesto que da cuenta del vínculo genético que existe entre los miembros del género humano, lo que necesariamente reconduce el estudio hacia la determinación de un concepto, que en tanto concepto abstracto que es, comprende todos los elementos específicos de nuestra especie y su protección alcanza incluso allí donde no puede hablarse de persona propiamente tal, es decir, ser humano nacido y vivo, cuya consecuencia es el "...necesario respeto por la condición humana y el deber de preservar su desarrollo futuro". Por ende, el genoma humano no es susceptible de apropiación material exclusiva y lucrativa, ya que los genes humanos son comunes a todas las generaciones; no obstante, ello no implica reconocer que la humanidad sea titular de un derecho subjetivo (fundamental o no), ya que según el autor ello sería "...forzar las categorías jurídicas que conocemos hasta hacerlas perder su propia configuración y utilidad" y en este sentido aboga más bien por la protección de valores o principios, y no de derechos en sentido estricto.

Desde una perspectiva subjetiva, implica el análisis de la protección de los genes de cada persona, lo que puede dar origen al reconocimiento de varios derechos constitucionales nuevos, entre ellos, el derecho a la integridad genética; a la identidad genética; y a la intimidad genética, que en general se vinculan con la protección e inviolabilidad del patrimonio genético de cada individuo, "...frente a intervenciones exteriores sobre el mismo... frente al conocimiento de la información genética por [parte de] terceros o por los poderes públicos, así como frente a actuaciones que pudieran utilizar ese patrimonio genético individual de forma discriminatoria o atentatoria contra otros derechos de la persona".

$\mathrm{Y}$ finalmente, ligado a las numerosas posibilidades que el avance genético ha proporcionado a las técnicas de reproducción asistida, se analiza también el derecho a la reproducción como derivación del libre desarrollo de la personalidad, el que cuenta con protección constitucional en España, postura que es avalada por la jurisprudencia constitucional ${ }^{6}$; por algunos 
textos internacionales y por la jurisprudencia del Tribunal Europeo de Derechos Humanos 7 . El autor se plantea en este punto si la protección constitucional del derecho a la reproducción implica que igualmente se encuentran amparados por la Constitución la utilización de todos los medios asistidos por la medicina para hacer efectivo el ejercicio de este derecho.

$\mathrm{Al}$ responder a este cuestionamiento, incluye el uso de las técnicas de reproducción asistida dentro del contenido esencial del derecho a la reproducción, puesto que estima que al tratarse de un derecho constitucional su efectividad va más allá de una simple obligación de no injerencia para los poderes públicos, ya que se trata de un derecho con claras facetas prestacionales. No obstante esta postura tiene un límite, ya que a su juicio deben excluirse del contenido esencial de este derecho todos aquellos procedimientos dirigidos no solo a la procreación, sino también a la selección de determinadas características genéticas en la descendencia.

A partir de estas premisas, se inicia una valoración jurídica de los principales procedimientos que involucran la alteración del genoma humano, ya sea modificándolo o introduciendo nuevos genes que dan lugar a un nuevo genotipo. Entre ellas destaca la terapia génica, la clonación, el diagnóstico genético preimplantatorio y la selección de embriones, las que son analizadas a la luz del valor de la dignidad humana. En cada una de ellas se realizan distinciones dependiendo de la finalidad que se persiga con la realización de la técnica de manipulación genética. Así, se distingue la finalidad terapéutica, que se enlaza directamente con la protección constitucional del derecho a la vida, a la integridad física y con el derecho a la salud; la finalidad de investigación o experimentación, que en principio se vincula con la protección constitucional de la libertad científica, pero que sin embargo sugiere la necesidad de establecer condiciones más estrictas para su realización, dependiendo del objeto de estudio: personas vivas, tejidos humanos, embriones, preembriones o células troncales; y la finalidad eugenésica, cuyo objetivo es la mejora de la raza, la que -a juicio del autor- no cuenta con una finalidad constitucionalmente legítima, puesto que implica una transgresión a la inviolabilidad del patrimonio genético de una persona, que por lo demás se transmite a la descendencia.

\section{2) CONSTITUCiÓN Y TECNOLOGÍAS DE LA INFORMACIÓN Y COMU- NICACIÓN}

En este capítulo se analizan las implicaciones que para los derechos constitucionales tienen los recientes desarrollos en el ámbito de las TIC, y

Tribunal Europeo de Derechos Humanos, sentencia de 10 de abril de 2007, caso Evans vs. Reino Unido y sentencia de 4 de diciembre de 2007, caso Dickson contra Reino Unido. 
en particular de Internet, los que han configurado toda una nueva forma de comunicación instantánea a lo largo y ancho del planeta, generando nuevos tipos de conductas sociales y culturales, convirtiéndose en un desafío más para las estructuras estatales y para las Constituciones.

Para ello se destaca la relación que existe entre el acceso y utilización de este tipo de tecnologías y los valores superiores consagrados en el artículo 1.1 de la Constitución española: la libertad, puesto que su ejercicio es facilitado por las TIC y al mismo tiempo impone un límite claro al momento de diseńar mecanismos de restricción para su acceso y funcionamiento; el pluralismo político, que en este contexto es posible entenderlo como una consecuencia de la libertad social de los individuos; y la igualdad, en tanto valor rector que guía no solo la prohibición de discriminación en el acceso y uso de las TIC, sino que también trae aparejado el deber de que los poderes públicos hagan real y efectiva esa igualdad y libertad de acceso, poniendo los medios adecuados para ello.

Así también, son muchos los derechos fundamentales vinculados con las nuevas tecnologías, los que pueden ser divididos en dos grupos básicos: los derechos relacionados directamente con la libertad (cobrando especial importancia el límite -hoy muy difuso- entre el ejercicio de la libertad de expresión e información y la libertad de comunicación, protegida por el secreto de las comunicaciones); y aquellos relacionados con la vida privada, en donde merece una especial referencia el derecho fundamental a la protección de datos personales, hoy ampliamente reconocido por la jurisprudencia espańola y europea.

A ellos también es posible sumar un listado más o menos profuso de derechos implicados en este ámbito, ya que como se manifiesta "prácticamente cualquier derecho muestra alguna implicación o dimensión vinculada a las nuevas tecnologías, o es susceptible de ejercicio utilizando estas", ya sea "a través" o "en" Internet, lo cual permite constatar que la relación entre las TIC y los derechos en la actualidad es "verdaderamente amplia y compleja”.

Junto a lo anterior, el autor también se plantea la posibilidad de poder argumentar en torno al reconocimiento de determinados "nuevos derechos" en este ámbito como lo es el derecho de acceder a las nuevas tecnologías o el derecho a la intimidad informática; así como también da cuenta de una serie de nuevas dimensiones o consecuencias que acarrea el ejercicio de los derechos fundamentales en el contexto virtual de Internet y de sus amenazas y problemas específicos, como por ejemplo en el caso de la libertad de expresión y opinión que hoy en día tiene secuelas imposibles de dimensionar, no solo en lo referente al ejercicio de este derecho, sino también con relación a la posible vulneración de otros derechos o valores; el derecho a la igualdad y su relación con la participación política (en donde hoy en día ha adquirido relevancia la posibilidad de ejercer el derecho a sufragio por vía electrónica por ejemplo), así como la partici- 
pación social, económica y cultural a través de Internet, cuestión de vital importancia para un Estado social y democrático de Derecho, entre otras muchas consideraciones que son sometidas a análisis en este capítulo.

Evidentemente, la pluma de Díaz Revorio en ningún caso agota la posibilidad de debatir en torno a un sinfín de cuestiones que solo alcanzan a quedar expuestas, pero que por el objeto de estudio resultan imposibles de abarcar, tal es por ejemplo el planteamiento de derechos no escritos como el derecho a conocer el origen biológico; el derecho a los padres o un derecho a recibir información veraz.

Sin embargo, ello no obsta para que esta obra se constituya en un aporte serio, reflexivo y de gran interés jurídico que asume el análisis de temas que han de conformar un constitucionalismo de carácter prospectivo, que busca otorgar a la Norma fundamental un sentido actual, que contemple al menos la posibilidad de reinterpretar los valores, principios y derechos fundamentales con un sentido evolutivo o de replantearnos ante las viejas estructuras e instituciones jurídicas para adaptarlas a una realidad, que en sí misma, es inabarcable para la lenta configuración de las respuestas que puede dar el Derecho o las normas jurídicas.

Esta labor indudablemente no resulta nada fácil, pero comparto con el autor que es absolutamente necesaria "la construcción de un nuevo Derecho constitucional, acorde con la nueva era histórica en la que sin duda hemos entrado", caracterizada por límites estatales "flexibles", por el impacto global del progreso científico y tecnológico, así como del surgimiento de necesidades éticas de protección de la dignidad ante cambios sociales y culturales impensables hasta hace solo unos lustros. Ello supone una continua labor de adaptación del fundamento axiológico de la Constitución, así como de su catálogo de derechos y la reelaboración de muchos conceptos que sirven de sustento a todo nuestro sistema jurídico (persona, dignidad, vida, libertad), pero sin renunciar al núcleo o fundamento último de todos ellos: la dignidad de las personas.

\section{Carolina Salas Salazar*}

Abogada. Doctora en Derecho Constitucional por la Universidad de Castilla - La Mancha (España). Profesora de Derecho Constitucional de la Universidad Católica del Norte, sede Coquimbo. Correo electrónico: csalas@ucn.cl 